\title{
CRITÉRIOS DE AVALIAÇÃO NO SETOR PÚBLICO: UM COMPARATIVO ENTRE UNIÃO X SEIS ESTADOS
}

\author{
EVALUATION CRITERIA IN THE PUBLIC COMPARATIVE SECTOR: A BETWEEN UNION X SIX \\ PROVINCES
}

DOI: http://dx.doi.org/10.12712/rpca.v6i3.182

\author{
Jaqueline Insaurriaga Silveira \\ jisilveira@ea.ufrgs.br \\ Escola de Administração - Universidade Federal do Rio Grande do Sul (EA/UFRGS) - Porto Alegre - RS, \\ Brasil
}

\section{Ivan Antônio Pinheiro}

iapinheiro@ea.ufrgs.br

Escola de Administração- Universidade Federal do Rio Grande do Sul (EA/UFRGS) - Porto Alegre - RS, Brasil

\section{Elaine Di Diego Antunes}

eddantunes@ea.ufrgs.br

Escola de Administração- Universidade Federal do Rio Grande do Sul (EA/UFRGS) - Porto Alegre - RS, Brasil

\section{Resumo}

Debatem-se os critérios de avaliação de desempenho dos servidores públicos quanto a sua clareza e objetividade, analisando-os nas normas estaduais dos Planos de Cargos e Carreiras do Poder Executivo e no Decreto Federal no. 7.133/2010. Demonstra-se que os estados do Mato Grosso, Mato Grosso do Sul, Minas Gerais, Piauí, Roraima e Tocantins contemplam a avaliação de desempenho. Constatou-se que os critérios dispostos na norma federal encontram-se nas legislações estaduais, contudo quanto à sua clareza e objetividade pode-se inferir que não guardam estreita relação com a consecução de metas individuais e institucionais, além, de possibilitar dubiedade e impressão em determinados casos.

Palavras-chave: Avaliação de Desempenho. Critérios de Desempenho. Servidores Públicos

\begin{abstract}
This study presents a discussion about the criteria for performance evaluation of public servants, pointing out their clarity and objectivity in the norms of the state, particularly regulations about the plan of career and position of the Executive Branch and the Federal law. 7.133/2010. The findings of this study suggest the states of Mato Grosso, Mato Grosso do Sul, Minas Gerais, Piauí, Tocantins and Roraima include performance evaluation. The study also shows the criteria of the federal's law are included in the norms of the state, but in terms of clarity and objectivity, it can be inferred that there are not close relation between them, specifically when concerns on the achievement of individual and institutional goals, opening the probability of doubts and interpretations in some cases.
\end{abstract}

Keywords: Performance Assessment. Performance Criteria. Public Servants 


\section{Introdução}

É inquestionável à importância da avaliação de desempenho no processo de gestão e como condição sine qua non para atingir os objetivos e metas; todavia, tudo parece mudar ao tratarse da avaliação de desempenho no setor público, sobretudo se individual. Assim, a introdução de instrumentos e modelos de avaliação contabiliza avanços e recuos através de iniciativas isoladas e erráticas, com prejuízos ao erário, gerando insegurança ou descontentamento entre os envolvidos.

É a partir da Reforma do Estado introduzida por L.C. Bresser Pereira, com a EC no 19/98 que o tema ganha relevância junto às instituições estatais, sendo considerado instrumento para identificar a insuficiência de desempenho para fins de perda de cargo público. Contudo, é quando a avaliação de desempenho individual - ADI, passa a ser utilizada para mensurar e estabelecer níveis de remuneração variável e complementar aos vencimentos básicos que o assunto ganha definitivo espaço na agenda da gestão de pessoas, ainda assim não sem receios e críticas de todos: servidores, cidadãos-usuários dos serviços públicos e gestores públicos. Desde 1993, se observa o crescimento na publicação de leis federais dispondo sobre planos de carreiras e instituindo o pagamento de gratificações, em que a ADI é determinante para apreciar o merecimento do servidor. No entanto, é partir de 2002 que a ADI vincula-se às metas institucionais, rompendo prática anterior, até então relacionada somente aos ganhos individuais: progressão, promoção ou recebimento de gratificação.

A profusão de iniciativas isoladas, algumas contrastantes, levou o governo federal a editar norma padronizadora - o Dec. Fed. no 7.133/10, um efetivo norte às futuras iniciativas. De outro lado, as iniciativas e a experiência federal tendem a ser reproduzidas nos âmbitos estadual e municipal, onde a trajetória observada não difere de todo do que já foi brevemente relatado. A avaliação de desempenho vinculada aos ganhos individuais, como será visto, tem sido a regra, à exceção do Estado de Minas Gerais, que através do Dec. Est. no $43.672 / 03$, Art. 5o , inciso XII, instituiu a avaliação de desempenho individual como o "instrumento de alinhamento das metas individuais com as institucionais” (MINAS GERAIS, 2003, p. 4).

Em se tratando de tema recente e controverso, que reúne interesses múltiplos, quando não conflitantes, e frente a tantas iniciativas, se revela oportuno um estudo descritivocomparativo objetivando responder às seguintes questões de pesquisa: quais critérios avaliativos têm sido utilizados?; é observada a objetividade?; a definição das metas individuais, de algum modo, está relacionada às metas organizacionais?; e por fim, entre outras, há uma consonância entre as normas estaduais (da amostra deste estudo) e o Decreto Federal? Os desdobramentos conforme seja a resposta a cada uma dessas questões serão distintos em termos de impactos, quer sobre os indivíduos - servidores -, quer sobre as unidades empregadoras e também sobre a sociedade. Para tanto, foram escolhidos para este estudo as iniciativas dos governos do Mato Grosso, Mato Grosso do Sul, Minas Gerais, Piauí, Roraima, Tocantins e, no caso do governo federal, a baliza foi o Decreto no $7.133 / 10$, por conseguinte, a base de dados não poderia ser outra que não a respectiva legislação pertinente aos casos estudados. 0 estudo foi realizado em 2010, baseado na legislação vigente.

\section{Avaliação de Desempenho na Gestão Pública: Breve Contexto}

No passado recente, teve-se a Lei Federal no 3.780/60, estabelecendo critérios como "pontualidade, assiduidade, capacidade, eficiência, espírito de colaboração, ética profissional, compreensão dos deveres e qualificação para o desempenho profissional" para promoção na carreira dos servidores (BRASIL, 1960, p. 8), critérios estes relacionados a traços comportamentais, que a priori, deveriam ser inerentes aos servidores e não objeto de avaliação para fins de promoção. A posteriori, o Dec. Fed. no 80.602/77 sinalizando a 
progressão funcional e o aumento por mérito através da avaliação dos servidores realizada pelo julgamento exclusivo da chefia em função do desempenho da unidade administrativa ou do comportamento funcional do servidor, sem haver instrumento específico para essa avaliação, explicitando a subjetividade do processo avaliativo na época, tendo sido revogado posteriormente pelo Dec. Fed. no 84.669/80, que instituía critérios como: "qualidade e quantidade do trabalho; iniciativa e cooperação, assiduidade e urbanidade; pontualidade e disciplina e antiguidade" (BRASIL, 1980, p. 10). Cabe lembrar que desde a década de 30, com a criação do Departamento de Administração do Serviço Público (DASP), já se buscava a implantação de um sistema de avaliação de desempenho no serviço público.

A crise e as transformações ocorridas nos anos 80, em especial a dos Estados, foi decisiva para a introdução de mudanças, de caráter estratégico, que viabilizassem o crescimento socioeconômico sem prejuízo à accountability e às estruturas de governança do setor público. No Brasil, a emenda constitucional para a Reforma Administrativa do Estado, definida no Plano Diretor de Reforma do Aparelho do Estado (PDRAE) em 1995 deu início à mudança na forma de gerir a máquina pública, dentre as ações estabelecidas: a (re)organização do Estado, a qualificação dos serviços prestados à sociedade, a reestruturação das carreiras, a capacitação permanente dos servidores, a participação dos servidores no estabelecimento de metas individuais em consonância com as metas institucionais, a valorização do servidor e a premiação dos melhores desempenhos. Dando andamento às ações do PDRAE, a EC nº. 19/98 dá nova redação ao art. 41 da CF (88), sinalizando a perda de cargo público por insuficiência de desempenho, constatada mediante avaliação periódica de desempenho. É sob essa atmosfera que a ADI ressurge não apenas como instrumento avaliador que visa à promoção e o crescimento na carreira pública, mas como instrumento gerencial que integra metas individuais com as metas institucionais, objetivando imprimir flexibilidade, qualidade e eficiência à gestão pública. Recentemente se têm a Lei Fed. no. 11.784/08, que reestrutura o Plano de Cargos do Poder Executivo e institui a gratificação de desempenho através da ADI mediante critérios de avaliação, e o Dec. no. 7.133/10 que vem regulamentar os critérios e os procedimentos do processo de avaliação de desempenho no serviço público federal.

O Relatório de Avaliação da Gestão de Recursos Humanos no Governo Federal, redigido pela OCDE em 2010, faz críticas à política de recursos humanos como sendo uma política fragmentada e incompleta, devido à falta de ações estratégicas sólidas e permanentes nas gestões anteriores e afirma que o sistema de avaliação de desempenho processado nas instituições federais não cumpre o papel a que se destina, tendo visto que, "os prêmios de desempenho passaram a fazer parte do salário regular da maioria do pessoal, perdendo o seu significado original de recompensa ao desempenho excepcional" (OCDE, 2010, p. 12).

Esforços foram empenhados na promoção da ADI no serviço público, contudo, a sua prática requer um tempo por ainda predominar uma cultura organizacional que resiste à "implantação de rotinas de aferição de desempenho mais efetivas" (BERGUE, 2010, p. 273).

\section{Critérios de Avaliação de Desempenho}

0 estabelecimento de critérios dependerá do que se pretende avaliar e do foco dessa avaliação, se o indivíduo, a organização, o cidadão-sociedade, ou qualquer outro. Avaliar os pares no ambiente organizacional pode ser uma tarefa árdua, devido às relações que se estabelecem entre os indivíduos. Segundo Marques (apud PAVANI JÚNIOR, 2003, p. 3),“se deve eliminar toda a subjetividade do processo e avaliar as pessoas pelos produtos que entregam à organização e não pelo humor que despertam em seus pares". Os critérios devem ser mensuráveis e condicionados a um planejamento, de forma a evitar a subjetividade na avaliação. Contudo, sabe-se que nem tudo, talvez o essencial, não seja mensurável. Mas, 
também, sabe-se da necessidade de se evitar a subjetividade no processo avaliativo e de se garantir um processo justo e que responda aos propósitos para o qual foi instituído. Segundo Rodrigues (2008), o erro de julgamento ou condescendência ao julgar é uma das causas frequentes na subjetividade da avaliação, visto que o avaliador pode exagerar positiva ou negativamente na avaliação. Ao encontro, Juliano (2008) afirma que a subjetividade é o fator mais relevante de um instrumento de avaliação, por ser o julgamento humano uma fonte de vulnerabilidade, contudo essa pode ser amenizada "por meio de um planejamento estratégico e sistemático que considere a definição dos critérios de avaliação de forma objetiva e observável, estabelecidos em conjunto com os envolvidos no processo, assim eliminando a subjetividade e diminuindo as chances da percepção do avaliador interferir no momento da avaliação" (JULIANO, 2008, p. 176).

Estabelecer critérios avaliativos pressupõe analisar as peculiaridades intrínsecas das carreiras ou grupos de carreiras. Segundo o Decreto no 7.133/2010, os critérios devem refletir as competências do servidor aliadas ao cumprimento das metas de desempenho individual e institucional (BRASIL, 2010).

\section{Coleta e Análise de Dados}

A coleta de dados se deu nas bases de dados dos poderes legislativos estaduais e da Presidência da República, tendo por expressões de busca os termos: avaliação de desempenho e critérios de avaliação. Dentre os documentos recuperados, selecionaram-se as normas referentes aos Planos de Cargos e Carreiras dos servidores efetivos da administração direta do Poder Executivo Estadual que contemplassem a avaliação de desempenho, e os decretos estaduais que conceituassem os critérios avaliativos. Para análise comparativa dos critérios, agruparam-se os mesmos conforme as similaridades encontradas. Quanto ao Decreto Federal, considerou-se o conceito literal dos critérios, visto que não estão explicitados. No Quadro 1 tem-se um resumo da base legal para a avaliação de desempenho nas unidades da amostra.

Quadro 1: Base legal para Avaliação de Desempenho - Comparativo temporal das legislações estaduais

\begin{tabular}{|c|c|c|c|c|c|}
\hline \multirow[t]{3}{*}{ ESTADO } & \multicolumn{5}{|c|}{ LEGISLAÇÃO ESTADUAL } \\
\hline & \multicolumn{2}{|c|}{ LEI } & \multicolumn{3}{|l|}{ DECRETO } \\
\hline & №/DATA & EMENTA & №/DATA & EMENTA & GOVERNO \\
\hline MT & $\begin{array}{l}\text { Lei Compl.n. } 04 \\
\text { 15/10/1990 }\end{array}$ & $\begin{array}{l}\text { Dispõe sobre o } \\
\text { Estatuto dos Serv. } \\
\text { Públicos [...] } \\
\end{array}$ & $\begin{array}{l}\text { Decreto n. } \\
3.006 \\
05 / 05 / 2004 \\
\end{array}$ & $\begin{array}{l}\text { Disciplina a Aval. Anual } \\
\text { de Desempenho [...] }\end{array}$ & $\begin{array}{l}\text { Blairo Borges } \\
\text { Maggi (PPS) }\end{array}$ \\
\hline MS & $\begin{array}{l}\text { Lei n. } 2.065 \\
29 / 12 / 1999\end{array}$ & 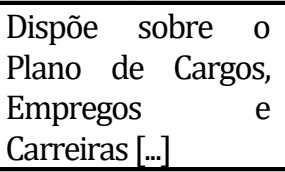 & $\begin{array}{l}\text { Decreto n. } \\
12.016 \\
28 / 12 / 2005\end{array}$ & $\begin{array}{l}\text { Dispõe sobre o sist. de } \\
\text { Avaliação de } \\
\text { Desempenho [...] }\end{array}$ & $\begin{array}{lr}\text { José } & \text { Orcírio } \\
\text { Miranda } & \text { dos } \\
\text { Santos (Zeca do } \\
\text { PT) }\end{array}$ \\
\hline MG & $\begin{array}{l}\text { Lei Compl. n. } 71 \\
\text { 30/07/2003 }\end{array}$ & $\begin{array}{l}\text { Institui avaliação de } \\
\text { desempenho, } \\
\text { institui perda de } \\
\text { cargo público[...] }\end{array}$ & $\begin{array}{l}\text { Decreto n. } \\
43.672 \\
04 / 12 / 2003\end{array}$ & $\begin{array}{l}\text { Estabelece diretrizes, } \\
\text { critérios, Sist. de Aval. } \\
\text { Desempenho }\end{array}$ & $\begin{array}{l}\text { Aécio Neves da } \\
\text { Cunha (PSDB) }\end{array}$ \\
\hline $\mathbf{R R}$ & $\begin{array}{l}\text { Lei } n . \quad 392 \\
14 / 08 / 2003\end{array}$ & $\begin{array}{l}\text { Dispõe sobre o } \\
\text { Plano de Cargos e } \\
\text { Salários [...] } \\
\end{array}$ & $\begin{array}{l}\text { Decreto } \\
6035-\mathrm{E} \\
29 / 10 / 2004 \\
\end{array}$ & $\begin{array}{ll}\text { Dispõe sobre Sist. de } \\
\text { Avaliação } & \text { de } \\
\text { Desempenho[...] } & \\
\end{array}$ & $\begin{array}{l}\text { Francisco } \\
\text { Flamarion Portela } \\
(\mathrm{PT})\end{array}$ \\
\hline PI & $\begin{array}{l}\text { Lei Compl.n. } 38 \\
\text { 24/03/2004 }\end{array}$ & $\begin{array}{l}\text { Dispõe sobre PCC } \\
{[\ldots . .]}\end{array}$ & $\begin{array}{l}\text { Decreto n. } \\
12.077 \\
02 / 02 / 2006 \\
\end{array}$ & $\begin{array}{l}\text { Regulamenta processo } \\
\text { de avaliação de } \\
\text { desempenho }\end{array}$ & $\begin{array}{l}\text { José Wellington } \\
\text { Barroso de Araújo } \\
\text { Dias (PT) }\end{array}$ \\
\hline T0 & $\begin{array}{l}\text { Lei n. } 1.534 \\
29 / 12 / 2004\end{array}$ & $\begin{array}{l}\text { Dispõe sobre PCC } \\
{[\ldots . .]}\end{array}$ & $\begin{array}{l}\text { Decreto n. } \\
2.551 \\
13 / 10 / 2005 \\
\end{array}$ & $\begin{array}{lr}\text { Dispõe sobre } & \begin{array}{r}\text { Aval. } \\
\text { Periódica }\end{array} \\
\text { Desempenho[...] } & \\
\end{array}$ & $\begin{array}{lr}\text { Marcelo } & \text { de } \\
\text { Carvalho } & \text { Miranda } \\
(\mathrm{PFL}) & \\
\end{array}$ \\
\hline
\end{tabular}

Fonte: Assembleias Legislativas Estaduais 


\section{Minas Gerais (MG)}

Minas Gerais institui a avaliação de desempenho pela LC no․ 71/03, sinalizando a perda de cargo público por insuficiência de desempenho e estabelece os critérios avaliativos pelo Dec. Est. no. 43.672/03. A perda de cargo público se dará após duas avaliações insatisfatórias consecutivas ou, em cinco avaliações três conceitos insatisfatórios intercalados. A ADI objetiva a valorização e o crescimento profissional do servidor, como também, a identificação de necessidades de capacitação e adequação funcional, de forma a contribuir para a promoção do princípio da eficiência na Administração Pública, bem como ser um instrumento de alinhamento de metas individuais com as institucionais. Sendo assim, é requisito para o cálculo de pagamento de Adicional de Desempenho - ADE; para o desenvolvimento na carreira; para o pagamento de prêmio por produtividade; para aplicação da pena de demissão por insuficiência de desempenho e para fins de dispensa de detentor de função pública (MINAS GERAIS, 2003, p. 4).

Quadro 2: Critérios avaliativos de desempenho - Minas Gerais

\begin{tabular}{|l|l|l|}
\hline$\#$ & CRITÉRIOS & DEFINIÇÕES \\
\hline $\mathbf{1}$ & Qualidade do trabalho & Grau de exatidão, correção e clareza dos trabalhos executados \\
\hline $\mathbf{2}$ & Produtividade no trabalho & Volume de trabalho executado em determinado espaço de tempo \\
\hline $\mathbf{3}$ & Iniciativa & $\begin{array}{l}\text { Comportamento proativo de atuação, busca garantir eficiência e eficácia na execução } \\
\text { dos trabalhos }\end{array}$ \\
\hline $\mathbf{4}$ & Presteza & Disposição para agir prontamente no cumprimento das demandas de trabalho \\
\hline $\mathbf{5}$ & $\begin{array}{l}\text { Aproveitamento em } \\
\text { programas de capacitação }\end{array}$ & $\begin{array}{l}\text { Aplicação dos conhecimentos adquiridos em atividades de capacitação na realização } \\
\text { dos trabalhos }\end{array}$ \\
\hline $\mathbf{6}$ & Assiduidade & Comparecimento regular e permanência no local de trabalho \\
\hline $\mathbf{7}$ & Pontualidade & $\begin{array}{l}\text { Observância do horário de trabalho e cumprimento da carga horária definida para o } \\
\text { cargo ocupado }\end{array}$ \\
\hline $\mathbf{8}$ & $\begin{array}{l}\text { Administração do tempo e } \\
\text { tempestividade }\end{array}$ & $\begin{array}{l}\text { Capacidade de cumprir as demandas de trabalho dentro dos prazos previamente } \\
\text { estabelecidos }\end{array}$ \\
\hline $\mathbf{9}$ & $\begin{array}{l}\text { Uso adequado equipamentos e } \\
\text { instalações de serviço }\end{array}$ & $\begin{array}{l}\text { Cuidado e zelo na utilização e conservação dos equipamentos e instalações no } \\
\text { exercício das atividades e tarefas }\end{array}$ \\
\hline $\mathbf{1 0}$ & $\begin{array}{l}\text { Aproveitamento dos recursos e } \\
\text { racionalização de processos }\end{array}$ & $\begin{array}{l}\text { Melhor utilização dos recursos disponíveis, visando à melhoria dos fluxos dos } \\
\text { processos de trabalho e a consecução de resultados eficientes. }\end{array}$ \\
\hline $\mathbf{1 1}$ & $\begin{array}{l}\text { Capacidade de trabalho em } \\
\text { equipe }\end{array}$ & $\begin{array}{l}\text { Capacidade de desenvolver as atividades e tarefas em equipe, valorizando o trabalho } \\
\text { em conjunto na busca de resultados comuns. }\end{array}$ \\
\hline
\end{tabular}

Fonte: Decreto Estadual no 43.672/2003

A pontuação dos critérios avaliativos não é atribuída igualmente, sendo que os critérios: (1) Qualidade do trabalho e (2) Produtividade no trabalho pontua 15\% cada. Do terceiro ao quinto critério a pontuação fica em $10 \%$ cada e finalmente, do sexto ao décimo primeiro critério cada um pontua 5\%. Infere-se com isso que a qualidade do trabalho e a produtividade no trabalho têm maior relevância na avaliação, provavelmente pelo fato de estarem relacionados ao princípio da eficiência no serviço público. Quanto aos critérios (6) Assiduidade, (7) Pontualidade e (9) Uso adequado dos equipamentos e instalações de serviço, são critérios questionáveis, visto serem fatores desejáveis ao comportamento profissional do servidor. É interessante observar, conforme exposto no Quadro 1, que o estado de MG é o que menos tempo levou entre a promulgação da lei que instituiu a avaliação de desempenho e o decreto estadual que dispôs sobre, ambos tendo ocorrido no mesmo ano, em 2003, e sob o mesmo governo político, sinalizando a sintonia entre o Executivo e Legislativo, sem a qual não teria havido quórum qualificado para aprovação na forma de LC. 


\section{Mato Grosso (MT)}

A avaliação de desempenho é instituída pela LC n⿳o. 04/90, que dispõe sobre o Estatuto dos Servidores Públicos da Administração Direta, das Autarquias e das Fundações Públicas Estaduais, e que disciplina, no art. 46, a progressão funcional do servidor que deve obedecer aos critérios especificados no Dec. Est. no. 3.006/04.

Quadro 3: Critérios avaliativos de desempenho - Mato Grosso

\begin{tabular}{|c|c|c|}
\hline$\#$ & CRITÉRIOS & DEFINIÇÕES \\
\hline \multirow[t]{3}{*}{1} & \multirow{3}{*}{$\begin{array}{l}\text { Comportamento no } \\
\text { trabalho }\end{array}$} & Cumpre a jornada de trabalho. \\
\hline & & Comunica chefia e membros de sua equipe as ausências necessárias durante expediente \\
\hline & & Cumpre os horários estabelecidos. \\
\hline \multirow[t]{4}{*}{2} & \multirow{4}{*}{$\begin{array}{l}\text { Qualidade no } \\
\text { trabalho }\end{array}$} & Realiza trabalhos sem necessidade de refazê-los , evitando deixar pendências. \\
\hline & & Executa trabalhos de acordo com exigências legais, determinações e normas aplicáveis. \\
\hline & & Ensina o trabalho sob sua responsabilidade a outros servidores, quando necessário. \\
\hline & & $\begin{array}{l}\text { Esclarece dúvidas dos clientes e de outros servidores quanto às rotinas sob a sua } \\
\text { responsabilidade. }\end{array}$ \\
\hline \multirow[t]{3}{*}{3} & \multirow[t]{3}{*}{ Iniciativa } & Apresenta sugestões para melhoria das rotinas sob a sua unidade \\
\hline & & Tem iniciativa de adquirir novos conhecimentos e habilidades no seu campo de atuação. \\
\hline & & Oferece ajuda quando detecta acúmulo de serviços no âmbito de sua unidade. \\
\hline \multirow[t]{3}{*}{4} & \multirow[t]{3}{*}{ Eficiência } & Executa as tarefas sem necessidade de intervenção do superior imediato. \\
\hline & & Cumpre metas pelas quais é responsável. \\
\hline & & $\begin{array}{l}\text { Cumpre os prazos estabelecidos, entregando as tarefas sob a sua responsabilidade no tempo } \\
\text { previsto. }\end{array}$ \\
\hline \multirow[t]{3}{*}{5} & \multirow[t]{3}{*}{ Responsabilidade } & $\begin{array}{l}\text { Mantém sigilo profissional de suas atividades e de outras que por força de suas atribuições tenha } \\
\text { conhecimento. }\end{array}$ \\
\hline & & Compromete-se com suas tarefas e com as metas estabelecidas pelo órgão ou entidade. \\
\hline & & Preserva a integridade dos equipamentos sob a sua responsabilidade. \\
\hline
\end{tabular}

Fonte: Decreto Estadual no. 3.006/2004

Institui cinco critérios que se subdividem em considerações a serem observadas dentro de cada grupo: (1) Comportamento no trabalho; (2) Qualidade no trabalho; (3) Iniciativa; (4) Eficiência; e (5) Responsabilidade. Importante destacar que no Decreto no. 3.006/04 há referência ao critério quantidade do trabalho e no formulário de avaliação consta qualidade no trabalho, conceitos bem distintos entre si. A pontuação dos mesmos varia de 0 (zero) a 10 (dez), em cada situação observada, sendo concedida a progressão vertical ao servidor que obtiver média igual ou superior a "60\% da pontuação máxima admitida, consideradas as avaliações anuais de desempenho dos três últimos exercícios" (MATO GROSSO, 2004, p. 2). No corpo do Decreto Estadual não há referência quanto à vinculação da avaliação de desempenho ao cumprimento de metas individuais ou institucionais previamente estabelecidas, somente no formulário de avaliação, no critério (5) Responsabilidade, faz-se menção com o comprometimento do servidor com metas estabelecidas pela instituição. 0 critério (5) também contempla a capacidade do servidor em manter sigilo profissional, relacionando-se a ética profissional, que presumivelmente deveria ser inerente ao comportamento profissional do servidor e não alvo de avaliação de desempenho. 0 mesmo ocorre com o critério (4) Eficiência, que constitui um dos princípios da administração pública. Diferentemente de MG, MT condiciona a progressão na carreira dos servidores à avaliação de desempenho, sem fazer referência na norma ao alcance de metas individuais e institucionais.

\section{Roraima (RR)}

Roraima institui a ADI pela Lei Estadual no. 392/03, que dispõe sobre o Plano de Cargos e Salários dos Servidores Públicos Efetivos do Quadro Geral de Pessoal do Poder Executivo 
Estadual, sinalizando a perda de cargo público por insuficiência de desempenho, e através do Dec. Est. no. 6.035-E/04 que regula o Sistema de Avaliação de Desempenho - SAD, o qual tem por finalidade aferir o desempenho do servidor segundo parâmetros de qualidade funcional combinados com parâmetros comportamentais e coletar informações necessárias a ações estratégicas de melhoria da qualidade dos serviços prestados à sociedade, pretendendo vincular a eficiência e a eficácia à estrutura institucional no desempenho dos serviços prestados à sociedade e servir de subsídios informacionais para a gestão de pessoal na administração estadual. (RORAIMA, 2003). O SAD institui avaliações distintas para os servidores de nível superior, nível médio e nível básico. Neste estudo utilizou-se o "Formulário 2A", que se refere a ADI dos servidores ocupantes de cargos de nível superior. Conforme o Decreto, a pontuação dos critérios avaliativos, se dará por conceitos atribuídos conforme a "percepção do avaliador em relação à frequência com que o avaliado demonstra resultados relativos ao exercício de suas atribuições e competências". Contudo, essa percepção pode não corresponder ao efetivo desempenho do servidor, visto a possibilidade de sofrer interferências do próprio avaliador, e dessa forma interferir no processo de avaliação.

Quadro 4: Critérios avaliativos de desempenho - Roraima

\begin{tabular}{|c|c|c|}
\hline \# & CRITÉRIOS & DEFINIÇÕES \\
\hline 1 & Planejamento do trabalho & $\begin{array}{l}\text { Formula objetivos, prevê procedimentos, recursos e prazos necessários ao cumprimento } \\
\text { das metas e diretrizes estabelecidas. }\end{array}$ \\
\hline 2 & $\begin{array}{l}\text { Conhecimento, } \\
\text { acompanhamento e } \\
\text { controle. }\end{array}$ & $\begin{array}{l}\text { Utiliza padrões técnicos adequados para assessorar, supervisionar, orientar, avaliar sobre } \\
\text { assuntos do seu campo de atuação. }\end{array}$ \\
\hline 3 & $\begin{array}{l}\text { Qualidade e organização do } \\
\text { trabalho }\end{array}$ & $\begin{array}{l}\text { Estabelece prioridades dos projetos e/ou atividades sob sua responsabilidade, com } \\
\text { eficiência e nos prazos estabelecidos. }\end{array}$ \\
\hline 4 & Perspicácia & $\begin{array}{l}\text { Percebe, pronta e integralmente, os detalhes de uma situação ou problema, seus } \\
\text { significados práticos e implicações. }\end{array}$ \\
\hline 5 & Visão sistêmica & Visualiza o conjunto de variáveis que integram os processos da organização. \\
\hline 6 & $\begin{array}{l}\text { Capacidade } \\
\text { empreendedora }\end{array}$ & $\begin{array}{l}\text { Prevê, analisa e resolve problemas relativos à sua área de atuação, criando alternativas } \\
\text { diante de situações novas. }\end{array}$ \\
\hline 7 & Responsabilidade & $\begin{array}{l}\text { Cumpri suas atribuições, assumindo e enfrentando as consequências de suas atitudes e } \\
\text { decisões. }\end{array}$ \\
\hline 8 & Comunicação & $\begin{array}{l}\text { Expressa-se, oralmente e por escrito, com clareza e objetividade, interpretando, utilizando } \\
\text { informações e todos os meios de comunicação necessários ao alcance dos resultados. }\end{array}$ \\
\hline 9 & Iniciativa & $\begin{array}{l}\text { Inicia uma atividade por conta própria, influenciando positivamente o curso dos } \\
\text { acontecimentos. }\end{array}$ \\
\hline $\begin{array}{l}1 \\
\mathbf{0}\end{array}$ & Criatividade & $\begin{array}{l}\text { Capacidade de produzir novos dados, idéias e/ou de realizar combinações originais, na } \\
\text { busca de uma solução eficiente e eficaz. }\end{array}$ \\
\hline $\begin{array}{l}1 \\
1\end{array}$ & Disciplina & Procede conforme normas, leis e regulamentos que regem a organização. \\
\hline $\begin{array}{l}1 \\
2\end{array}$ & Camaradagem & Estabelece relações amistosas com superiores, pares e com o público. \\
\hline $\begin{array}{l}1 \\
3\end{array}$ & Equilíbrio emocional & $\begin{array}{l}\text { Maneja bem suas emoções, apresentando adequada resposta emocional nas diferentes } \\
\text { situações. }\end{array}$ \\
\hline $\begin{array}{l}1 \\
4\end{array}$ & Autodesenvolvimento & Busca, por iniciativa própria, aperfeiçoamento pessoal e profissional. \\
\hline $\mathbf{1}$ & Comportamento ético & $\begin{array}{l}\text { Mantém comportamento ético condizente com o ambiente de trabalho, respeitando o } \\
\text { espaço institucional e os integrantes da equipe. }\end{array}$ \\
\hline
\end{tabular}

Fonte: Decreto Estadual no. 6.035-E/2004

Comparativamente a MG e MT, Roraima institui novos critérios avaliativos: (4) Perspicácia; (5) Visão sistêmica; (8) Comunicação; (12) Camaradagem; (13) Equilíbrio emocional, critérios 
que podem ser interessantes ao valorizarem competências individuais, contudo, por outro lado, podem dar margem a questões legais, visto que, o servidor pode se sentir injustiçado com a avaliação recebida, pois indivíduos distintos apresentam competências e capacidades distintas, e a presença ou deficiência de uma competência pode não invalidar o efetivo desempenho do servidor.

\section{Tocantins (TO)}

Tocantins institui a ADI pela Lei Estadual no. 1.534/04 que regula o Plano de Cargos, Carreiras e Subsídios dos Servidores Públicos [...] e institui o Sistema de Avaliação de Desempenho e Qualificação Funcional, o qual tem por finalidade aprimorar métodos de gestão, valorizando a atuação do servidor. A regulamentação da avaliação de desempenho deu-se no ano posterior a promulgação da Lei, através do Decreto Estadual no. 2.551/05, o qual conceitua a ADI como um instrumento utilizado periodicamente para aferir os resultados alcançados pela atuação do servidor no exercício de suas funções, segundo parâmetros de qualidade dos serviços prestados, tendo por objetivos valorizar, capacitar e aperfeiçoar o servidor no seu desempenho funcional, promover ações de orientação e superação de deficiências, bem como de integração organizacional, além de instruir os processos de progressão funcional e aprimorar o desempenho da Administração Pública Estadual.

São utilizados treze formulários distintos, para servidores de nível superior, de nível médio e de nível fundamental. Para fins desse estudo, analisou-se o formulário 3A, correspondente a avaliação de servidores de nível superior, visto ser o que mais similaridades apresenta com os estabelecidos nos outros Estados analisados.

Quadro 5: Critérios avaliativos de desempenho - Tocantins

\begin{tabular}{|c|c|c|}
\hline \# & CRITÉRIOS & DEFINIÇÕES \\
\hline 1 & $\begin{array}{l}\text { Conhecimento do } \\
\text { serviço }\end{array}$ & $\begin{array}{l}\text { Domínio técnico do seu campo de atuação, com conhecimento de todos os processos e rotinas } \\
\text { de trabalho e interação com os objetivos do órgão, bem como da Administração Pública } \\
\text { Estadual. }\end{array}$ \\
\hline 2 & $\begin{array}{l}\text { Iniciativa e } \\
\text { cumprimento de prazos }\end{array}$ & $\begin{array}{l}\text { Grau de iniciativa na solução dos problemas e exatidão no cumprimento das atividades, } \\
\text { dentro dos prazos previstos. }\end{array}$ \\
\hline 3 & Eficiência & $\begin{array}{l}\text { Capacidade para simplificar as atividades de trabalho, resolvendo-as de maneira satisfatória, } \\
\text { independente da qualidade ou quantidade dos meios disponíveis. }\end{array}$ \\
\hline 4 & Qualidade do trabalho & $\begin{array}{l}\text { Dispensa cuidados na execução de suas tarefas, apresentando resultados eficientes: clareza, } \\
\text { exatidão, correção. }\end{array}$ \\
\hline 5 & Disciplina & Capacidade de proceder conforme normas, leis e regulamentos que regem a organização. \\
\hline 6 & Organização & $\begin{array}{l}\text { Estabelece prioridades aos projetos/atividades sob sua responsabilidade, ordenando-os } \\
\text { adequadamente. }\end{array}$ \\
\hline 7 & Atenção concentrada & $\begin{array}{l}\text { Capacidade de focalizar a percepção numa determinada tarefa e assim mantê-la, mesmo sob } \\
\text { constantes interferências ambientais. }\end{array}$ \\
\hline 8 & Alcance dos objetivos & Realiza todos os projetos e atividades sob sua responsabilidade. \\
\hline 9 & Comunicação & Capacidade de expressar ideias com lógica e objetividade, por escrito e oralmente. \\
\hline $\begin{array}{l}\mathbf{1} \\
\mathbf{0}\end{array}$ & Adaptabilidade & $\begin{array}{l}\text { Lida com situações novas e/ou pressões de trabalho, ajustando-se à mudança de orientação } \\
\text { técnico-administrativa de interesse do órgão. }\end{array}$ \\
\hline $\begin{array}{l}1 \\
1\end{array}$ & Subordinação & $\begin{array}{l}\text { Apresenta adequado grau de disposição em receber suporte e direção de seu superior, } \\
\text { atuando em conformidade com o ambiente. }\end{array}$ \\
\hline $\begin{array}{l}1 \\
2\end{array}$ & Atendimento & $\begin{array}{l}\text { Atende às demandas dos usuários com atenção e cortesia. Tem consciência do seu papel no } \\
\text { serviço público. }\end{array}$ \\
\hline $\begin{array}{l}1 \\
3\end{array}$ & Sociabilidade & Capacidade de estabelecer relações amistosas com superiores, colegas e usuários dos serviços. \\
\hline $\begin{array}{l}1 \\
4\end{array}$ & Trabalho em equipe & $\begin{array}{l}\text { Capacidade de desenvolver trabalhos em equipe, mantendo uma postura profissional } \\
\text { participativa e colaboradora. }\end{array}$ \\
\hline
\end{tabular}

Fonte: Decreto Estadual no. 2.551/2005 
Originalmente, no Decreto, os critérios de (1) a (10) estão categorizados em Competências funcionais e os de (11) a (14) em Competências comportamentais. Neste estudo, optou-se por não categorizá-los, devido a análise comparativa entre os estados. Quanto ao sistema de pontuação, o mesmo se dá pela utilização de conceitos conforme a escala: 1 = Insatisfatório; 2 = Regular; 3 = Bom; 4 = Ótimo; $5=$ Excepcional. Os critérios avaliativos seguem a mesma linha dos anteriormente expostos nos textos legais de MG, MT e RR, salvo as diferenças já apresentadas. A novidade está na indicação do critério (7) Atenção concentrada como critério avaliativo, o que indica certa subjetividade, por ser a capacidade de concentração um elemento distinto em cada indivíduo e necessariamente não sinônimo de efetivo desempenho. Capacidades distintas de concentração podem gerar diferentes produtos.

\section{Mato Grosso do Sul (MS)}

A ADI, instituída pela Lei Est. no․ 2.065/99, que dispõe sobre o Plano de Cargos, Empregos e Carreiras da Administração Direta e Indireta do Poder Executivo Estadual, é considerada um dos fatores a serem observados no sistema de promoção do servidor, tendo por objetivo "aferir o rendimento, a performance e o desenvolvimento do servidor no exercício do cargo ou função." Também, sinaliza os critérios de avaliação e determina que os mesmos "poderão ser adaptados em conformidade com as peculiaridades das funções do cargo exercido pelo servidor e com as atribuições do órgão a que esteja vinculado." (MATO GROSSO DO SUL, 1999, p. 14). Interessante observar que a norma não engessa os critérios avaliativos, sendo que os mesmos podem ser adaptados, conforme peculiaridades específicas. Sinaliza doze critérios que servem de orientação às posteriores processos de avaliação. Seis anos após a promulgação da Lei n‥ 2.065/99 é publicado o Dec. Est. no. 12.016/05, que dispõe sobre o Sistema de Avaliação de Desempenho e tem por objetivo "medir o desempenho individual do servidor e identificar as necessidades de treinamento e desenvolvimento, bem como apontar deficiências de recursos materiais e das condições de trabalho" (MATO GROSSO DO SUL, 2005, p. 8). Não há uma referência explícita a consecução de metas individuais e institucionais no corpo do decreto, somente no critério (5) Produtividade no trabalho, exposto no Quadro 6 há uma referência ao alcance de metas.

Quadro 6: Critérios avaliativos de desempenho - Mato Grosso do Sul

\begin{tabular}{|l|l|l|}
\hline$\#$ & CRITÉRIOS & DEFINIÇÕES \\
\hline $\mathbf{1}$ & $\begin{array}{l}\text { Assiduidade e } \\
\text { pontualidade }\end{array}$ & $\begin{array}{l}\text { Qualidade do avaliado de ser assíduo e pontual, por meio dos registros da frequência ao } \\
\text { trabalho, sem atrasos, saídas antecipadas ou durante o expediente e as ausências. }\end{array}$ \\
\hline $\mathbf{2}$ & $\begin{array}{l}\text { Iniciativa e } \\
\text { presteza }\end{array}$ & $\begin{array}{l}\text { Identificar a aptidão para tomar decisões e a dedicação do avaliado no desempenho de } \\
\text { suas atribuições e na resolução de problemas de rotina ou imprevistos, a capacidade de } \\
\text { buscar e indicar alternativas ou novos padrões para resolver situações cuja solução excede } \\
\text { aos procedimentos de rotina, apresentar propostas novas e assumir, de forma } \\
\text { independente, desafios, responsabilidades e liderança de trabalhos em relação aos colegas } \\
\text { e chefias. }\end{array}$ \\
\hline $\mathbf{3}$ & $\begin{array}{l}\text { Disciplina e zelo } \\
\text { funcional }\end{array}$ & $\begin{array}{l}\text { Determinar a conduta do avaliado no exercício da função pública em relação ao respeito às } \\
\text { leis e às normas disciplinares, o comportamento e o cumprimento de ordens recebidas, } \\
\text { assim como o caráter ético profissional demonstrado na execução de tarefas com } \\
\text { probidade, lealdade, decoro, zelo e valorização do elemento ético. }\end{array}$ \\
\hline $\mathbf{4}$ & $\begin{array}{l}\text { Qualidade de } \\
\text { trabalho }\end{array}$ & $\begin{array}{l}\text { Verificar o desempenho correto das tarefas de responsabilidade do avaliado e a qualidade } \\
\text { dos trabalhos, considerando o nível de confiabilidade, exatidão, clareza e ordem, a } \\
\text { utilização correta dos recursos disponíveis, a participação no encaminhamento de soluções } \\
\text { para os problemas que se apresentam, bem como sua aptidão e domínio de conhecimentos } \\
\text { técnicos demonstrados na realização de tarefas rotineiras. }\end{array}$ \\
\hline $\mathbf{5}$ & $\begin{array}{l}\text { Produtividade no } \\
\text { trabalho }\end{array}$ & $\begin{array}{l}\text { Apurar capacidade e habilidade de desenvolver trabalhos, de obter resultados com o } \\
\text { menor custo possível, considerando quantidade, cumprimento de prazos e atingimento de } \\
\text { objetivos ou metas, bem como a responsabilidade pelas atividades desenvolvidas e a } \\
\text { realização dos trabalhos planejados e a consecução dos seus objetivos. }\end{array}$ \\
\hline
\end{tabular}




\begin{tabular}{|c|c|c|}
\hline 6 & $\begin{array}{l}\text { Urbanidade no } \\
\text { tratamento }\end{array}$ & $\begin{array}{l}\text { Avaliar a conduta pessoal no relacionamento com o público, colegas e superiores, o } \\
\text { comportamento ético e educação, assim como a obediência ao conjunto dos princípios que } \\
\text { orientam a conduta do servidor público. }\end{array}$ \\
\hline 7 & $\begin{array}{l}\text { Aproveitamento } \\
\text { em programas de } \\
\text { capacitação }\end{array}$ & $\begin{array}{l}\text { Comprovar a capacidade de melhorar o desempenho das atribuições normais da função e a } \\
\text { realização de tarefas superiores, e de maior complexidade, adquiridas em estudos, } \\
\text { trabalhos específicos e participação em cursos regulares relacionados com atribuições do } \\
\text { cargo, promovidos pela administração pública. }\end{array}$ \\
\hline 8 & $\begin{array}{l}\text { Administração do } \\
\text { tempo }\end{array}$ & $\begin{array}{l}\text { Apurar o esforço e a capacidade de execução do trabalho que lhe é confiado, utilizando } \\
\text { adequadamente seu horário de trabalho, a demonstração da capacidade para distinguir as } \\
\text { tarefas, priorizando aquelas de maior urgência. }\end{array}$ \\
\hline 9 & $\begin{array}{l}\text { Uso adequado dos } \\
\text { equipamentos de } \\
\text { serviço }\end{array}$ & $\begin{array}{l}\text { Apurar o cuidado com materiais de trabalho, demonstrando preocupação com a sua } \\
\text { manutenção e bom uso e empenhando-se em sua economia e conservação. }\end{array}$ \\
\hline 10 & Chefia e liderança & $\begin{array}{l}\text { Computar grau de responsabilidade na condução de pessoas e o poder decisório envolvido, } \\
\text { por meio do exercício de cargo em comissão ou função de confiança, considerando } \\
\text { capacidade para coordenar trabalho de pessoas para consecução dos objetivos de } \\
\text { programas, projetos ou atividades e a posição hierárquica do órgão ou unidade, seja na } \\
\text { condição de ocupante efetivo ou substituto. }\end{array}$ \\
\hline 11 & $\begin{array}{l}\text { Participação em } \\
\text { órgão de } \\
\text { deliberação } \\
\text { coletiva }\end{array}$ & $\begin{array}{l}\text { Computar a participação e atuação como membro de órgão colegiado de deliberação } \\
\text { coletiva, considerando a condição de efetivo ou suplente e a posição hierárquica do órgão } \\
\text { no processo decisório da administração Pública Estadual ou do respectivo órgão ou } \\
\text { entidade. }\end{array}$ \\
\hline 12 & $\begin{array}{l}\text { Cultura } \\
\text { profissional e } \\
\text { geral }\end{array}$ & $\begin{array}{l}\text { Apreciar a capacidade e o esforço pessoal em aperfeiçoar-se para aprender novos } \\
\text { processos de trabalho e a busca de novos e melhores alternativas que facilitem a realização } \\
\text { profissional, através da identificação da participação em cursos de formação ou capacitação } \\
\text { para aperfeiçoamento pessoal e profissional. }\end{array}$ \\
\hline
\end{tabular}

Fonte: Decreto Estadual no‥ 12.016/2005

A pontuação dos critérios segue os seguintes parâmetros: Ótimo; Bom; Regular; Fraco; e Insatisfatório. No corpo da Lei nº. 2.065/99, os critérios são categorizados em: Condições fundamentais, critérios de (1) a (3); Condições essenciais, de (4) a (6); e Condições complementares, de (7) a (12). No entanto, optou-se, por não categorizá-los, respeitando a apresentação do Decreto e do formulário avaliativo. Os critérios apresentam uma particularidade: cinco dos doze critérios dispostos estão vinculados a outro critério, formando um critério composto, por exemplo: (1) Assiduidade e Pontualidade; (2) Iniciativa e Presteza; (3) Disciplina e Zelo funcional. Contudo, essa composição de critérios pode gerar uma dificuldade para o avaliador, visto que o servidor pode atender somente a uma parte do critério. A novidade é o critério (11) Participação em órgão de deliberação coletiva.

\section{Piauí (PI)}

A LC nº. 38/04, que dispõe sobre o Plano de Cargos, Carreira e Vencimento dos Servidores Públicos [...] no seu art.37 determina sobre as duas formas básicas de avaliação de desempenho: a avaliação de características relacionadas ao desempenho de cargo ou função, considerando os critérios avaliativos; e a avaliação de características relacionadas à formação, capacitação e profissionalização do servidor. No artigo seguinte sinaliza que a avaliação de desempenho deverá servir, "prioritariamente, à identificação de situações de desempenho funcional deficiente, irregular ou insatisfatório, com o propósito de corrigir distorções e necessidades de aperfeiçoamento e capacitação profissional." (PIAUÍ, 2004, p. 10). Percebe-se pelo texto legal, que a prioridade da avaliação é identificar e corrigir desempenhos insatisfatórios e necessidades de capacitação do servidor, não fazendo referência ao cumprimento de metas individuais ou institucionais. No art. 13 do Dec.no. 12.077/06 são instituídos os critérios avaliativos de desempenho em cargo ou função (vide Quadro 7). 
Quadro 7: Critérios avaliativos de desempenho - Piauí

\begin{tabular}{|c|c|c|}
\hline \# & CRITÉRIOS & DEFINIÇÕES \\
\hline 1 & Assiduidade & Frequência do servidor ao trabalho. \\
\hline 2 & Pontualidade & Cumprimento do horário de trabalho. \\
\hline 3 & Responsabilidade & Capacidade de responder satisfatoriamente inerente ao seu cargo. \\
\hline 4 & Disciplina & Cumprimento pelo servidor de normas regulamentos e instruções da unidade. \\
\hline 5 & Eficiência & Rendimento no trabalho em termos quantitativos e qualitativos. \\
\hline 6 & Produtividade & Produto da eficiência. \\
\hline 7 & Iniciativa e Presteza & Atitude do servidor para por vontade própria buscar soluções para os problemas. \\
\hline 8 & Urbanidade & $\begin{array}{l}\text { Qualidade do atendimento dado pelo servidor ao usuário e postura ética nas relações } \\
\text { profissionais. }\end{array}$ \\
\hline 9 & $\begin{array}{l}\text { Administração do } \\
\text { tempo }\end{array}$ & Qualidade no resultado do trabalho em tempo hábil. \\
\hline 10 & Chefia e Liderança & $\begin{array}{l}\text { Ação social voltada para envolver pessoas na busca de objeto comum, guiar a equipe em } \\
\text { torno de um objetivo da sua área de atuação }\end{array}$ \\
\hline 11 & $\begin{array}{l}\text { Cultura geral e } \\
\text { profissional }\end{array}$ & $\begin{array}{l}\text { Nível de conhecimento técnico-científico e social, que tem acerca da sua área de atuação e } \\
\text { áreas correlatas. }\end{array}$ \\
\hline 12 & $\begin{array}{l}\text { Consecução de } \\
\text { metas e objetivos }\end{array}$ & $\begin{array}{l}\text { Capacidade do servidor em atingir metas e objetivos estabelecidos em um determinado } \\
\text { prazo. }\end{array}$ \\
\hline
\end{tabular}

Fonte: Decreto Estadual no. 12.077/2006

Identifica-se novamente a presença dos critérios (1) Assiduidade e (2) Pontualidade, como critérios avaliativos, como se não fossem uma obrigatoriedade do servidor. Também, o critério Eficiência, apresenta-se alvo de avaliação, mesmo constituindo um dos princípios da administração pública. Importa destacar a instrução do critério (12), o qual se refere ao desempenho do servidor na obtenção de metas estabelecidas em um período determinado, até então, citado somente em T0, porém como (8) Alcance de objetivos. A pontuação dos critérios dar-se-á por conceito e nota, conforme os seguintes parâmetros: I = Insatisfatório: de 0 a 29; $\mathrm{R}=$ Regular: de 30 a 49; $\mathrm{B}=$ Bom: de 50 a 69; $\mathrm{MB}=$ Muito bom: de 70 a 89; $\mathrm{E}=$ Excelente: de 90 a 100.

\section{Decreto Federal №. 7.133}

O Dec. Fed. n 7.133/10 dispõe que a ADI consiste no "monitoramento sistemático e contínuo da atuação individual do servidor [...] tendo como referência as metas globais e intermediárias [...]", e esclarece que a avaliação terá por base critérios que reflitam "as competências do servidor, aferidas no desempenho individual das tarefas e atividades a ele atribuídas." (BRASIL, 2010, p. 6). Quanto aos critérios avaliativos, dispõe que além do cumprimento das metas individuais de desempenho, deverão ser atendidos os critérios: (1) Produtividade no trabalho; (2) Conhecimento de métodos e técnicas profissionais; (3) Trabalho em equipe; (4) Comprometimento com o trabalho; (5) Cumprimento de normas de procedimentos e conduta; e um ou mais dos critérios: (6) Qualidade técnica do trabalho; (7) Capacidade de autodesenvolvimento; (8) Capacidade de iniciativa; (9) Relacionamento interpessoal; e (10) Flexibilidade às mudanças. Destarte, o Decreto Federal somente orienta a instituição de critérios, cabendo a cada órgão federal estabelecer seus próprios critérios de avaliação tanto individual quanto institucional, respeitando os fatores mínimos dispostos no decreto. No entanto, caso ocorram diferenças entre as disposições do Decreto e as das Leis específicas dos Planos de Cargos ou de Carreiras ou da Gratificação de Desempenho, prevalece às mencionadas nas Leis. O Decreto Federal inova diante da possibilidade de ganhos distintos entre os servidores, relativo ao pagamento das gratificações, na medida em que a pontuação aferida no processo de avaliação é relativa ao desempenho individual de cada servidor, ou seja, quem pontuar mais receberá mais, é claro que dentro de uma escala de pontuação já 
estabelecida. Outra novidade refere-se ao fato do servidor ser avaliado pela chefia, por sua equipe de trabalho e se auto avaliar. E mais, os servidores com avaliação individual inferior a $50 \%$ dos pontos passarão por processo de capacitação ou adequação funcional, e para efeitos de pagamento, a distribuição será pela avaliação institucional (até 80 pontos) e individual (até 20 pontos), realizadas anualmente (CHARLSON, 2010).

\section{Comparando os Critérios Avaliativos}

Analisou-se comparativamente os 69 critérios dispostos nos decretos estaduais e os 10 dispostos no Dec. Fed. n․ 7.133/10 organizando-os conforme suas similaridades conceituais, resultando num conjunto de 38 critérios avaliativos. Referente à norma de MG, o critério (8) Administração do tempo e tempestividade, fica sendo Administração do tempo; (9) Uso adequado dos equipamentos e instalações de serviço fica Zelo pelos equipamentos e instalações de serviço. Para os sinalizados na norma de MT, o critério (1) Comportamento no trabalho, fica sendo Assiduidade e o critério (5) Responsabilidade fica Comprometimento com o trabalho. Roraima passa a ter renomeado o critério (7) Responsabilidade, que fica entendido como Comprometimento com o trabalho e o critério (12) Camaradagem como Urbanidade. Em T0, o critério (1) Conhecimento do serviço, fica sendo Conhecimento de métodos e técnicas de trabalho; (10) Adaptabilidade, passa a ser considerado Flexibilidade às mudanças; (12) Atendimento, fica sendo Urbanidade; e (14) Trabalho em equipe, passa a ser Capacidade de trabalho em equipe. Para MS, o critério: (2) Iniciativa e presteza, passa a ser identificado como Iniciativa; (3) Disciplina e zelo funcional, como Disciplina; (4) Qualidade de trabalho, como Qualidade do trabalho; (5) Produtividade no trabalho, como Produtividade; (6) Urbanidade no tratamento como Urbanidade; e (9) Uso adequado dos equipamentos de serviço como Zelo pelos equipamentos e instalações de serviço. E, finalmente, referente ao PI, consideraram-se os critérios: (3) Responsabilidade, como Comprometimento com o trabalho; e (12) Consecução de metas e objetivos, como Alcance de metas e objetivos.

Quadro 8: Comparativo dos critérios avaliativos de desempenho

\begin{tabular}{|c|c|c|c|c|c|c|c|c|}
\hline \multicolumn{2}{|c|}{ CRITÉRIOS } & \multicolumn{6}{|c|}{ ESTADOS } & \multirow{3}{*}{$\begin{array}{l}\text { UNIÃo } \\
2010\end{array}$} \\
\hline & & \multirow{2}{*}{\begin{tabular}{|l|} 
MG \\
2003 \\
$X$ \\
\end{tabular}} & \multirow{2}{*}{$\begin{array}{l}\text { MT } \\
2004 \\
\end{array}$} & \multirow{2}{*}{$\begin{array}{l}\mathbf{R R} \\
2004 \\
\end{array}$} & \multirow{2}{*}{$\begin{array}{l}\text { T0 } \\
2005 \\
\end{array}$} & \multirow{2}{*}{$\begin{array}{l}\text { MS } \\
2005 \\
X\end{array}$} & \multirow{2}{*}{$\begin{array}{l}\text { PI } \\
2006 \\
X\end{array}$} & \\
\hline 1 & Administração do tempo & & & & & & & \\
\hline 2 & Organização & & & & $\mathrm{X}$ & & & \\
\hline 3 & Qualidade e organização do trabalho & & & $\mathrm{X}$ & & & & \\
\hline 4 & Alcance dos objetivos & & & & $X$ & & $X$ & \\
\hline 5 & Aproveitamento programas de capacitação & $\mathrm{X}$ & & & & $\mathrm{X}$ & & \\
\hline 6 & Assiduidade & $\mathrm{X}$ & $\mathrm{X}$ & & & & $\mathrm{X}$ & \\
\hline 7 & Assiduidade e pontualidade & & & & & $\mathrm{X}$ & & \\
\hline 8 & Pontualidade & $\mathrm{X}$ & & & & & $\bar{X}$ & \\
\hline 9 & Atenção concentrada & & & & $\mathrm{X}$ & & & \\
\hline 10 & Autodesenvolvimento & & & $\mathrm{X}$ & & & & $\mathrm{X}$ \\
\hline 11 & Cultura geral e profissional & & & & & $X$ & $\mathrm{X}$ & \\
\hline 12 & Capacidade de trabalho em equipe & $\mathrm{X}$ & & & $\mathrm{X}$ & & & $\mathrm{X}$ \\
\hline 13 & Capacidade empreendedora & & & $\mathrm{X}$ & & & & \\
\hline 14 & Planejamento do trabalho & & & $\mathrm{X}$ & & & & \\
\hline 15 & Chefia e Liderança & & & & & $\mathrm{X}$ & $\mathrm{X}$ & \\
\hline 16 & Comportamento ético & & & $\mathrm{X}$ & & & & \\
\hline 17 & Comprometimento com o trabalho & & $\mathrm{X}$ & $\mathrm{X}$ & & & $\mathrm{X}$ & $\mathrm{X}$ \\
\hline 18 & Comunicação & & & $\mathrm{X}$ & $\mathrm{X}$ & & & \\
\hline
\end{tabular}




\begin{tabular}{|l|l|l|l|l|l|l|l|l|}
\hline $\mathbf{1 9}$ & Conhecimento, acompanhamento e controle & & & $\mathrm{X}$ & & & & \\
\hline $\mathbf{2 0}$ & Conhecimento de métodos e técnicas de trabalho & & & & $\mathrm{X}$ & & & $\mathrm{X}$ \\
\hline $\mathbf{2 1}$ & Criatividade & & & $\mathrm{X}$ & & & & \\
\hline $\mathbf{2 2}$ & Disciplina & & & $\mathrm{X}$ & $\mathrm{X}$ & $\mathrm{X}$ & $\mathrm{X}$ & $\mathrm{X}$ \\
\hline $\mathbf{2 3}$ & Eficiência & & $\mathrm{X}$ & & $\mathrm{X}$ & & $\mathrm{X}$ & \\
\hline $\mathbf{2 4}$ & Aproveita recursos eracionaliza processos & $\mathrm{X}$ & & & & & & \\
\hline $\mathbf{2 5}$ & Equilíbrio emocional & & & $\mathrm{X}$ & & & & \\
\hline $\mathbf{2 6}$ & Flexibilidade às mudanças & & & & $\mathrm{X}$ & & & $\mathrm{X}$ \\
\hline $\mathbf{2 7}$ & Iniciativa & $\mathrm{X}$ & $\mathrm{X}$ & $\mathrm{X}$ & & $\mathrm{X}$ & $\mathrm{X}$ & $\mathrm{X}$ \\
\hline $\mathbf{2 8}$ & Iniciativa e Cumprimento de prazos & & & & $\mathrm{X}$ & & & \\
\hline $\mathbf{2 9}$ & Presteza & $\mathrm{X}$ & & & & & & \\
\hline $\mathbf{3 0}$ & Participação em órgãos de deliberação coletiva & & & & & $\mathrm{X}$ & & \\
\hline $\mathbf{3 1}$ & Perspicácia & & & $\mathrm{X}$ & & & & \\
\hline $\mathbf{3 2}$ & Produtividade & $\mathrm{X}$ & & & & $\mathrm{X}$ & $\mathrm{X}$ & $\mathrm{X}$ \\
\hline $\mathbf{3 3}$ & Qualidade do trabalho & $\mathrm{X}$ & $\mathrm{X}$ & & $\mathrm{X}$ & $\mathrm{X}$ & & $\mathrm{X}$ \\
\hline $\mathbf{3 4}$ & Subordinação & & & & $\mathrm{X}$ & & & \\
\hline $\mathbf{3 5}$ & Urbanidade & & & $\mathrm{X}$ & $\mathrm{X}$ & $\mathrm{X}$ & $\mathrm{X}$ & $\mathrm{X}$ \\
\hline $\mathbf{3 6}$ & Sociabilidade & & & & $\mathrm{X}$ & & & \\
\hline $\mathbf{3 7}$ & Zelo pelos equipamentos einstalações de serviço & $\mathrm{X}$ & & & & $\mathrm{X}$ & & \\
\hline $\mathbf{3 8}$ & Visão sistêmica & & & $\mathrm{X}$ & & & & \\
\hline
\end{tabular}

Fonte: Decretos Estaduais e o Decreto Federal no. 7.133/2010

Comparando os critérios estaduais com da norma Federal, observa-se que os critérios mais frequentes nas normas estaduais são: (22) Disciplina, com quatro ocorrências; (27) iniciativa, com cinco; (33) qualidade do trabalho, também com quatro; e (35) urbanidade, igualmente com quatro ocorrências, sendo que esses critérios também estão sinalizados no Dec. n⿳o. 7.133/10; já os menos citados, todos com somente uma ocorrência e em consonância com a norma federal são: (10) autodesenvolvimento; (20) conhecimento de métodos e técnicas de trabalho; (26) flexibilidade às mudanças.

Constata-se que um mesmo critério comporta diferentes definições nas normas estaduais, o que dificulta estudos comparativos; a exemplo do critério Cultura geral e profissional apresentado em MS e PI, sendo que para o MS ele se relaciona à capacidade do servidor em buscar por meios próprios seu aperfeiçoamento, o que estaria mais de acordo com o critério Autodesenvolvimento indicado por RR. Já para PI, relaciona-se ao nível de conhecimento técnico e de áreas correlatas à função exercida pelo servidor. Igualmente o critério Eficiência sinalizado em MT, TO e PI, apresenta nuances distintas em sua conceituação, visto que para MT, a eficiência está relacionada ao cumprimento de metas e prazos; já para T0, relaciona-se a resolução satisfatória de demandas, independentemente dos recursos disponíveis; e para PI encontra-se relacionado ao rendimento no trabalho em termos quantitativos e qualitativos. Já os critérios Organização, e Qualidade e organização, indicados em RR e TO, guardam similaridade entre si, visto que ambos referem-se à capacidade de priorizar projetos e demandas de serviço. Contudo, para RR qualidade e organização compõem um único critério avaliativo, já para T0, são critérios independentes. Para fins de análise comparativa mantevese o disposto na legislação.

Observa-se que Roraima institui critérios mais distintos dos outros analisados e também do Dec. Fed., a exemplo: Capacidade empreendedora, Planejamento do trabalho, Comportamento ético, Equilíbrio emocional, Perspicácia e Visão sistêmica. Ademais, MS é o único estado a indicar o critério Participação em órgão de deliberação coletiva como critério avaliativo. 
Outro aspecto a considerar é quanto aos critérios Alcance dos objetivos; e Consecução de metas e objetivos indicados no quadro comparativo (Quadro 8) como Alcance de metas e objetivos, visto que somente TO e PI instituem esse critério para avaliar o desempenho do servidor; embora o Dec. Fed. n․ 7.133/10, que antes de introduzir os critérios avaliativos, expõe que cabe ao servidor o cumprimento de metas de desempenho individual, não indicando claramente esse critério como sendo um critério a ser observado. Dentre os estados analisados, RR é o estado que mais critérios atribui para o processo de avaliação, instituindo quinze critérios, seguido por TO, com quatorze, enquanto MT é o que apresenta menor número, com apenas cinco indicados. Os outros estados, MG, PI e MS ficam entre onze e treze critérios; e, o Decreto Federal orienta a instituição de dez critérios avaliativos.

\section{Considerações Finais}

Tema recente, e ainda com poucos estudos, este trabalho teve por objetivo identificar os critérios de avaliação de desempenho dispostos nas legislações estaduais e contrastá-los com os disciplinados no Dec. Fed. no. 7.133/10. Foram percebidas, assim, além das categorias, as suas definições, graus de objetividade ou subjetividade, peso relativo, entre outros aspectos, em especial a vinculação ou não, da ADI ao desempenho organizacional. Pode-se observar que os critérios dispostos na norma federal estão contemplados nas normas estaduais dos estados analisados. Contudo, quanto à clareza e objetividade dos mesmos infere-se que há margem para dubiedade e imprecisão no processo de avaliação, visto que ao se instituir critérios como Perspicácia, Visão sistêmica e Comunicação, permite-se que haja uma interferência subjetiva do avaliador, o que deve ser algo a ser evitado.

Quanto à consonância com metas estabelecidas, infere-se que a relação não é estreita, pois há critérios específicos ao comportamento e capacidades do servidor. Somente o PI institui o critério Consecução de metas e objetivos, relatando o estabelecimento de prazos, embora TO indique o critério Alcance de objetivos, porém referindo-se ao cumprimento de tarefas sob a responsabilidade do servidor. Minas Gerais refere-se a ADI como instrumento de alinhamento de metas individuais com as institucionais, porém não institui critério específico. Chamou sobremodo a atenção, ter como critério de avaliação, indicativos de comportamentos que não deveriam fazer parte de um processo de avaliação para posterior premiação, visto referiremse a comportamentos funcionais presumíveis de um servidor público.

\section{Referências}

BERGUE, Sandro Trescastro. Gestão de pessoas em organizações públicas. 3.ed. rev. e atual. Caxias do Sul: EDUCS, 2010.599 p., il.

BRASIL. Decreto no 84.669, de 29 de abril de 1980. Disponível em: < http://www.planalto.gov.br/ccivil 03/decreto/1980-1989/D84669.htm > Acesso em 25 jun. 2010.

. Decreto no. 7.133, de 19 de março de 2010. Regula os critérios e procedimentos gerais a serem observados nas avaliações de desempenho individual e institucional e o pagamento das gratificações de desempenho. Disponível em: http://www.planalto.gov.br/ccivil 03/Ato2007-2010/2010/Decreto/D7133.htm >. Acesso em: 17 jun. 2010.

. Lei no. 3.780, de 12 de julho de 1960. Dispõe sobre a classificação de cargos do serviço civil do Poder Executivo, estabelece os vencimentos correspondentes, e dá outras providências. Disponível em: < http://www6.senado.gov.br/legislacao/ListaPublicacoes.action?id=112978 >. Acesso em 17 
jun. 2010.

CHARLSON, Freddy. Decreto regulamenta a avaliação de desempenho. Servidor Público Federal. Disponível em: < http://servidorpblicofederal.blogspot.com/2010/03/decretoregulamenta-avaliacao-de 24.html > Acesso em: 31 jul. 2010.

GHELMAN, Sílvio. Análise ambiental do processo de avaliação de desempenho do Inmetro. In: Congresso Internacional del CLAD sobre la Reforma del Estado y d la Administración Pública, 13., 2008, Buenos Aires. Disponível em:< http://www.mp.gov.br/hotsites/seges/clad/documentos/ghelman.pdf $>$. Acesso em 27 jun. 2010.

JULIANO, Marcio de Cássio. Aspectos conceituais da avaliação de desempenho. Anuário da Produção Acadêmica Docente, v. 2, n. 3, 2008. Disponível em: $<$ http://sare.unianhanguera.edu.br/index.php/anudo/article/viewFile/677/519> Acesso em 03 set. 2011.

MARQUES, Wellington Pereira. Aprenda a avaliar sua equipe por desempenho. Disponível em : <http://www.gaussconsulting.com.br/imagens/artigos/artigo avaliacao desempenho Wellington Marques.pdf $>$ Acesso em: 03 set. 2011.

MATO GROSSO. Decreto no. 3.006, de 05 de maio de 2004. Disciplina a avaliação anual de desempenho para fins de progressão vertical. Disponível em: http://www.sefaz.mt.gov.br/portal/Institucional/DecretoN30062004AvaliacaoAnuadeDese mp.pdf >. Acesso em: 14 jun. 2010.

MATO GROSSO DO SUL. Decreto no. 12.016, de 28 de dezembro de 2005. Dispõe sobre o Sistema de Avaliação de Desempenho dos Servidores Efetivos de Carreiras do Plano de Cargos e Carreiras do Poder Executivo. Disponível em: < http://aacpdappls.net.ms.gov.br/appls/legislacao/secoge/govato.nsf/1b758e65922af3e9042 56b220050342a/ed5ce6396846d42e042570e6004fb24f?OpenDocument>. Acesso em 17 jun. 2010.

. Lei no. 2.065, de 29 de dezembro de 1999. Dispõe sobre o Plano de Cargos, Empregos e Carreiras da Administração Direta e Indireta do Poder Executivo do Estado e dá outras providências. Disponível em: <http://aacpdappls.net.ms.gov.br/appls/legislacao/secoge/govato.nsf/448b683bce4ca8470 4256c0b00651e9d/effe9150e363ad8e04256c000059495e? OpenDocument >. Acesso em: 17 jun. 2010.

MINAS GERAIS. Lei Complementar no. 71, de 30 de julho de 2003. Institui a Avaliação Periódica de Desempenho Individual, disciplina a perda de cargo público e de função pública por insuficiência de desempenho. Disponível em: < http://hera.almg.gov.br/cgi-bin/nphbrs?co1=e\&d=NJMG\&p=1\&u=http://www.almg.gov.br/njmg/chama pesquisa.asp\&SECT1=I MAGE\&SECT2=THESOFF\&SECT3=PLUROFF\&SECT6=HITIMG\&SECT7=LINKON\&l=20\&r=1\&f= G\&s1=LCP.TIPO.+e+71.NUME.+e+2003.ANO.\&SECT8=SOCONS >. Acesso em: 15 jun. 2010.

OCDE. Avaliação da Gestão de Recursos Humanos no Governo - Relatório da OCDE: Brasil 2010, Governo Federal. [Paris]: OCDE, 2010. Disponível em: < http://www.planejamento.gov.br/secretarias/upload/Arquivos/noticias/srh/100520 estudo OCDE.pdf >. Acesso em: 05 jul. 2010.

PAVANI JÚNIOR, Orlando. Gerenciamento por objetos: a administração vetorial. São Paulo: Epse, 2003. 
PIAUÍ. Lei Complementar no. 38, de 24 de março de 2004. Dispõe sobre o Plano de Cargos, Carreira e Vencimento dos Servidores Públicos Civis da Adminsitração Direita, Autárquica e Fundacional do Estado do Piauí. Disponível em: < http://legislacao.pi.gov.br/scan/pages/jsp/scan/consultaDeAtoNormativo.jsp?idAtoNormati $\underline{\mathrm{vo}=582}>$. Acesso em 17 jun. 2010.

RODRIGUES, Antônio. Avaliação de desempenho nas organizações: desvantagens do processo tradicional. 2008. Disponível em:< http://pt.scribd.com/doc/6089651/Avaliacao-deDesempenho-Nas-Organizacoes-do-Processo-Tr>. Acesso em 03 set. 2011.

RORAIMA Lei n⿳o. 392, de 14 de agosto de 2003. Dispõe sobre o Plano de Cargos e Salários dos Servidores Públicos Efetivos do Quadro Geral de Pessoal do Poder Executivo do Estado de Roraima e dá outras providências. Disponível em: <http://www.escoladegoverno.rr.gov.br/escRR/Lei 392.doc>. Acesso em: 14 jun. 2010. 